\title{
Free-Flight Testing in the Gas-Driven Two-Stage Light Gas Gun HEK-G
}

\author{
By Hideyuki Tanno, Tomoyuki Komuro, Masatoshi Kodera, Kazuo SAto and Katsuhiro Itoh ${ }^{1)}$ \\ ${ }^{1)}$ Japan Aerospace Exploration Agency Kakuda Space Center, Miyagi, Japan
}

(Received June 24th, 2011)

\begin{abstract}
The current status of free-flight testing with the gas driven two-stage light gas gun in JAXA Kakuda was reported. Modifications of the gun were followings. (1) Maximum pressure of the pump tube end section was increased from 100MPa to 200MPa, (2) Test section for $15 \mathrm{~mm}$ gun barrel was extended from $5 \mathrm{~m}$ to $6.5 \mathrm{~m}$ with an additional optical windows located at the test section, (3) 4-pieces sabot for $15 \mathrm{~mm}$ diameter gun barrel (4) High-speed video camera and high-wattage light source. (5) Newly built $72 \mathrm{~mm}$ diameter gun barrel for $50 \mathrm{~mm}$ diameter projectiles and (6) 2-pieces sabot for $72 \mathrm{~mm}$ diameter gun barrel. The $15 \mathrm{~mm}$ diameter gun barrel was going to be used for the study for aerodynamics under hypersonic condition. The $72 \mathrm{~mm}$ diameter gun barrel was going to be used for the study on the aerodynamic instability of re-entry capsules under transonic to supersonic condition. In a test campaign with the $15 \mathrm{~mm}$ diameter gun barrel, we have launched $5 \mathrm{~mm}$ diameter sphere projectiles with 4-piecies sabot at a velocity at the gun barrel muzzle of $2.1 \mathrm{~km} / \mathrm{s}$ to $3.8 \mathrm{~km} / \mathrm{s}$. We successfully observed sabot separation and projectile ( $5 \mathrm{~mm}$ diameter steel sphere) release through the high-speed video camera. In a test campaign with the $72 \mathrm{~mm}$ diameter gun barrel, we successfully conducted to launch Apollo shaped capsule projectile of 50mm diameter with 2-pieces sabot at a velocity at the gun barrel muzzle was approximately $430 \mathrm{~m} / \mathrm{s}$. Our in-housed quasi-one-dimensional Navier-Stokes code was applied to determine safety operation condition of the $72 \mathrm{~mm}$ gun barrel and to estimate projectile speed.
\end{abstract}

Key Words: Ballistic Range, Two-Stage Light Gas Gun, Free-Flight

\section{Introduction}

Since 2007, JAXA started to research on aero-ballistic range for the purpose of free-flight ground test ${ }^{1)}$. A free-piston shock tunnel HEK (High Enthalpy shock tunnel in Kakuda) in JAXA was modified to the gas driven two-stage light gas gun HEK-G. The major feature of this facility is the free-piston driver, which enables the driver piston fully reusable, resulting to the low cost and short turn-round operation. For the performance prediction and design of the facility, a quasi-one dimensional NavierStokes code was applied to simulate gas-dynamics with piston and projectile motion. The gun has mainly focused to produce free-flight aerodynamic data as a benchmark to evaluate wind tunnels and numerical simulations.

In the fiscal year 2010, we upgraded several points of the facility. Since aerodynamic instability of capsule shapes under transonic flow becomes important technical issue in JAXA, we modified the gun mainly for transonic testing with larger projectiles. The latest test results obtained with the upgraded HEK-G were reported in this paper.

\section{Upgrade of the Two-Stage Light Gas Gun HEK-G}

As already reported in the previous paper ${ }^{1)}$, the two-stage light gas gun HEK-G was a facility modified from the high-enthalpy shock tunnel $\mathrm{HEK}^{2)}$. Since HEK was originally built as freepiston shock tunnel, which driver produces high-pressure and high-temperature helium gas through adiabatic compression process with a heavy piston, HEK-G also has the remarkable feature as the followings.

(1) Fully reusable piston: This feature will shorten the turn round time to re-set up the facility. The operation cost can also be reduced accordingly.
(2) No gun-powder: Low erosion rate of the pump tube. Unnecessity of special equipment and permission (Japanese domestic regulation) to handling of gun powder.

(3) Wide operation envelope: Pump tube pressure can be varied from $2 \mathrm{MPa}$ to $200 \mathrm{MPa}$.It can allow flexibility to adjust operation condition for different mass projectile under required launch velocity.

A test campaign in FY2010, we upgraded HEK-G as the shown in the below.

(1) High-pressure pump tube: Pump tube pressure $100 \mathrm{MPa}$ to 200MPa.

(2) Extended test section and an additional optical window: Test section was extended to $5 \mathrm{~m}$ to $6.5 \mathrm{~m}$ for the installation of target plate holder. Number of optical window was increased from three stations to four stations.

(3) 4-pieces sabot for the $15 \mathrm{~mm}$ diameter gun barrel: In order to launch steel bearing for high-speed impact testing into test plates.

(4) High-speed video camera (SHIMAZU Hypervision) and high-wattage light source.

(5) Newly built $72 \mathrm{~mm}$ bore gun barrel: For the purpose of the aerodynamic test with re-entry capsules.

(6) 2-pieces sabot for the $72 \mathrm{~mm}$ diameter gun barrel.

The $72 \mathrm{~mm}$ diameter gun barrel was built for the purpose of the free-flight tests to measure aerodynamic instability of reentry capsules at transonic to supersonic speed. Since the HEK free-piston driver was originally designed for $72 \mathrm{~mm}$ diameter gun barrel (Shock tube), we expected that the driver can operate ideal condition. In Fig.1, the schematics and a photograph of the newly built $72 \mathrm{~mm}$ bore gun barrel were shown. The gun barrel was made of 18-8 stainless steel (SUS-304), which length was $2.5 \mathrm{~m}$. In order to avoid effects of shock waves reflection from the test section wall, the projectile is going to be launched 
into open test space instead of the closed test section. The length of the free-flight measurement section was $2.5 \mathrm{~m}$. Finally, the projectile is going to be caught by projectile catcher, which was a boxed structure made from two layers of poly-urethane forms, five layers of Kevlar sheets and bread-board (shown as Fig.2).
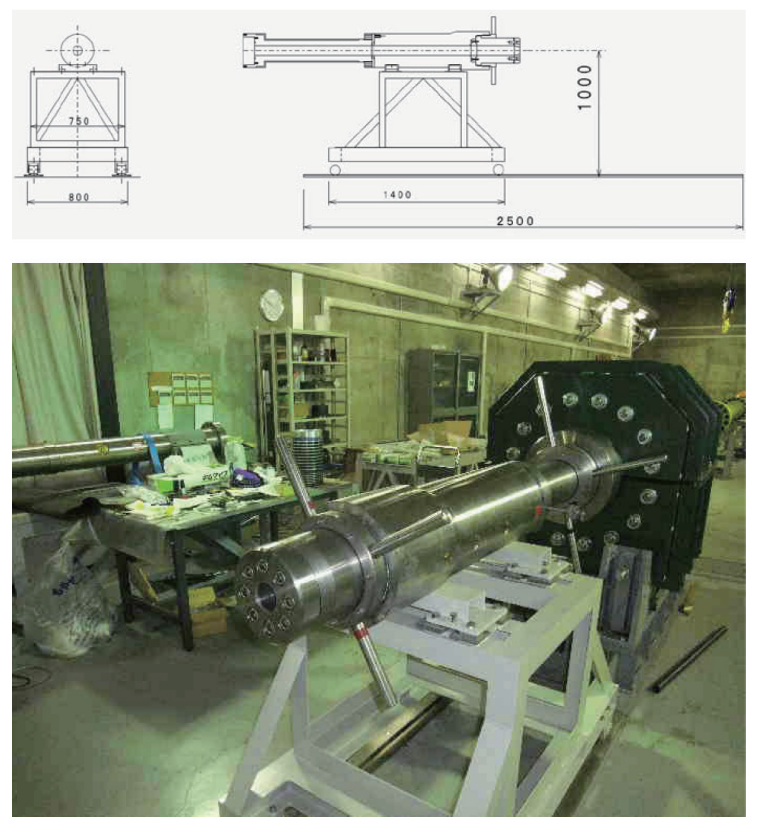

Fig.1. $72 \mathrm{~mm}$ bore newly built gun barrel for transonic free-flight test.

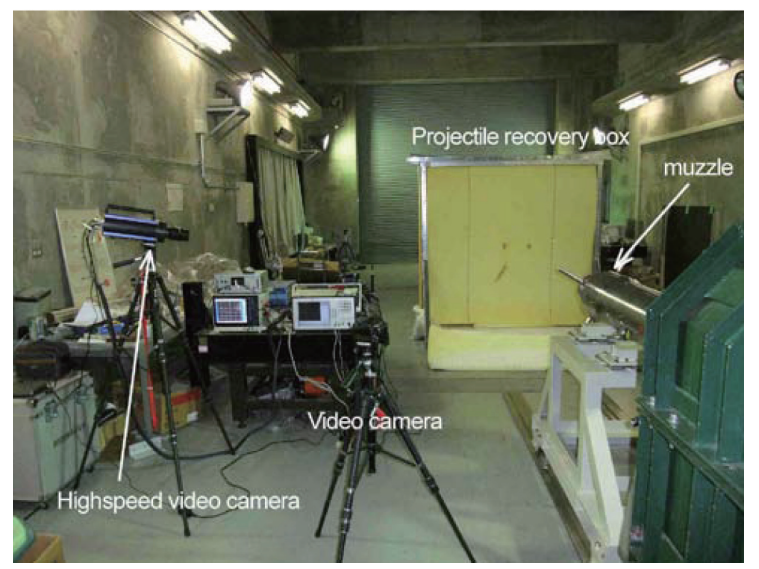

Fig.2. Projectile recovery box. Five layers of yellow Kevler sheets and poly-urethane forms were located to mitigate projectile damage.

\section{Numerical Simulation}

The numerical code used in this study was quasi onedimensional Navier-Stokes finite differential code based on 2nd order KRC scheme ${ }^{3)}$. In the preliminary test campaign in the last FY, we already verified the code can accurately predict the safety operation conditions for HEK-G with $15 \mathrm{~mm}$ bore gun barrel. In this test campaign, numerical calculation was conducted to determine safety operation condition with the $72 \mathrm{~mm}$ gun barrel.

For safety operation and fully reusable piston, it is essential to achieve soft landing piston at the end of pump tube. As already described above, the original driver of HEK was applied in this study, the air reservoir and the pump tube dimension was fixed. Hence, the adjustable parameters to control the operation condition are the secondary reservoir initial pressure the pump tube initial pressure and piston mass.

Since the purpose of $72 \mathrm{~mm}$ bore gun barrel was for the aerodynamic testing with reentry capsules under transonic to supersonic speed, pump tube condition (pressure) must be quite lower than original design. For the transonic speed with $260 \mathrm{~g}$ projectile, the rapture pressure of main diaphragm was $2 \mathrm{MPa}$. Secondary reservoir pressure was $0.2 \mathrm{MPa}$ accordingly. In FY2010, the maximum pressure of the pump tube in the HEK was increased from $100 \mathrm{MPa}$ to $200 \mathrm{MPa}$, the rapture pressure of the main diaphragm was hence extremely out of standard operation condition. As shown in the Fig.3 (top figure), pump tube pressure should be above main diaphragm burst pressure (2MPa). Piston soft landing condition was also evaluated with the piston trajectory as shown in the middle of the figure. As shown in the bottom of the figure, we adjust the secondary reservoir initial pressure and pump tube initial pressure to achieve the projectile speed approximately Mach $1.4(420 \mathrm{~m} / \mathrm{s})$. Operation condition was finally decided as shown in the Table.1.
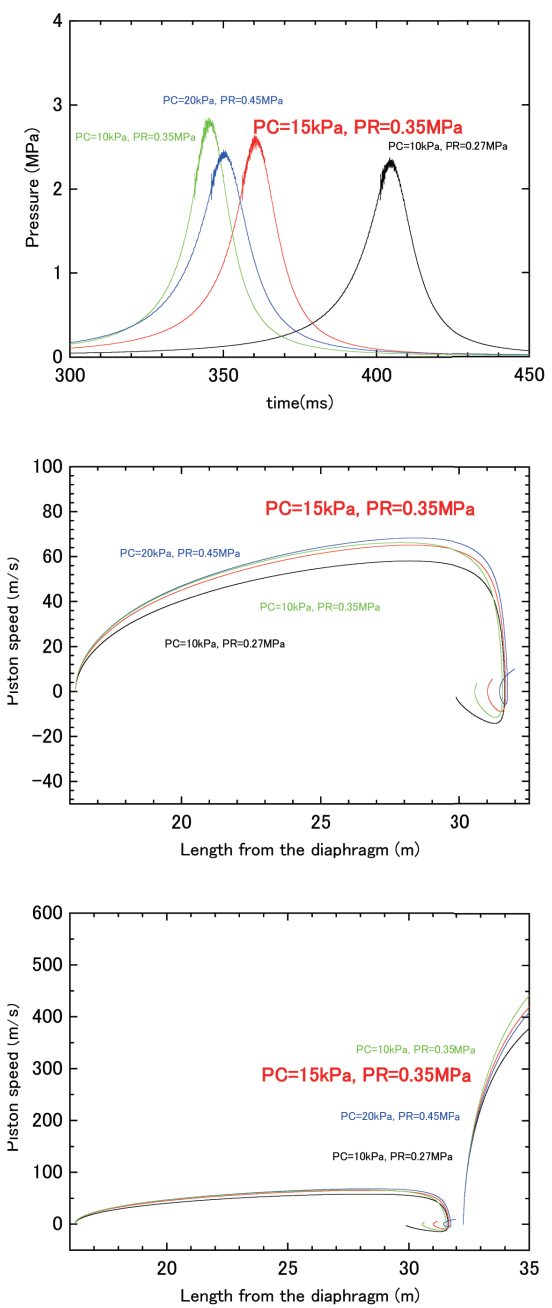

Fig.3. Numerical simulation results to tune the operation condition for $72 \mathrm{~mm}$ bore gun barrel. (top)Pump tube pressure history, (middle)piston trajectory and (bottom)projectile trajectory were shown. 


\begin{tabular}{cc} 
Table.1 Test condition of HEK-G with $72 \mathrm{~mm}$ bore gun barrel. \\
\hline Secondary resovoir pressure (MPa) & 0.35 \\
Piston mass ( $\mathrm{kg}$ ) & 25.7 \\
Pump tube (Pump tube) initial pressure $(\mathrm{kPa})$ & 12 \\
diaphragm rapture pressure (MPa) & 2 \\
Gun barrel length $(\mathrm{m})$ & 2 \\
Projectile mass $(\mathrm{g})$ & 260
\end{tabular}

\section{Results}

\section{1. $15 \mathrm{~mm}$ gun barrel}

With the $15 \mathrm{~mm}$ diameter gun barrel, $5 \mathrm{~mm}$ diameter steel spheres (steel bearing, mass 5g. shown in the Fig.4) were used as projectiles. In the $15 \mathrm{~mm}$ gun barrel test campaign in this FY2010, main purpose was the verification of a prototype sabot Operation condition of the pump tube was hence fixed to the condition determined in the test campaign last year (shown in table 2). To measure projectile speed, two set of lasers and photo-detectors were instrumented as shown in Fig.5 (top). Laser 1 was located at the exit of the gun barrel, while Laser 2 was located $445 \mathrm{~mm}$ behind the Laser 1 position. Projectile speed was calculated with time of flight measured from these two photo-detector outputs. One of the photo-detectors outputs were also used as the trigger signal for the high-speed video camera. The high-speed video image (Fig.6) showed that the projectile was successfully released from the 4-pieces sabot. Through the test campaign, test section pressure was changed from $1 \mathrm{kPa}$ to $10 \mathrm{kPa}$ to observe aerodynamic effect on sabot separation. Sabot separation was also clearly shown as footprints on the target plates shown in the Fig.6. The hole in the middle of the each plate was the projectile penetration.

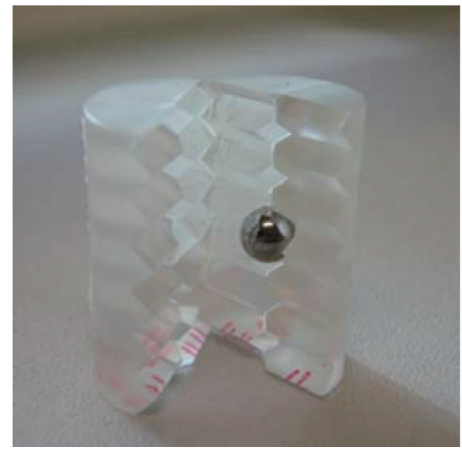

Fig.4. $5 \mathrm{~mm}$ steel sphere installed in 4-pieces sabot.

\begin{tabular}{cc} 
Table.2 Test condition of HEK-G with $15 \mathrm{~mm}$ bore gun barrel. \\
\hline Secondary resovoir pressure (MPa) & 1.1 \\
Piston mass $(\mathrm{kg})$ & 25.7 \\
Pump tube (Pump tube) initial pressure $(\mathrm{kPa})$ & 45 \\
diaphragm rapture pressure $(\mathrm{MPa})$ & 10 \\
Gun barrel length $(\mathrm{m})$ & 4 \\
Projectile mass $(\mathrm{g})$ & 6
\end{tabular}

\section{2. $72 \mathrm{~mm}$ gun barrel}

In the beginning of the present test campaign with $72 \mathrm{~mm}$ diameter gun barrel, system check of this newly built gun barrel was conducted. The free-piston driver was operated under the condition as already shown in Table 1, which was decided by the numerical prediction code. Through the test campaign, we successfully operated the facility without any damage on the facility (includes free-piston and piston buffer at the end of
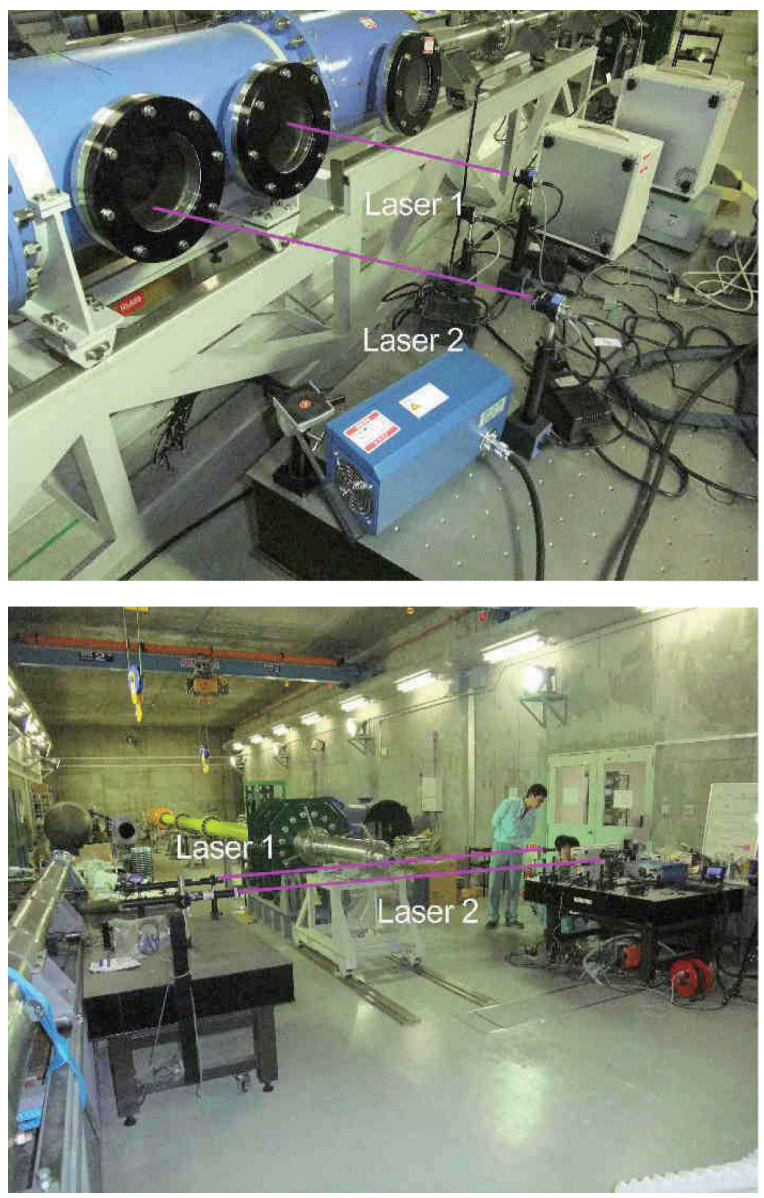

Fig.5. Lunch tube and test section of the gun. Two sets of lasers and detectors were instrumented to measure projectile speed. Top: setup for the $15 \mathrm{~mm}$ gun barrel. Bottom: setup for the $72 \mathrm{~mm}$ gun barrel.

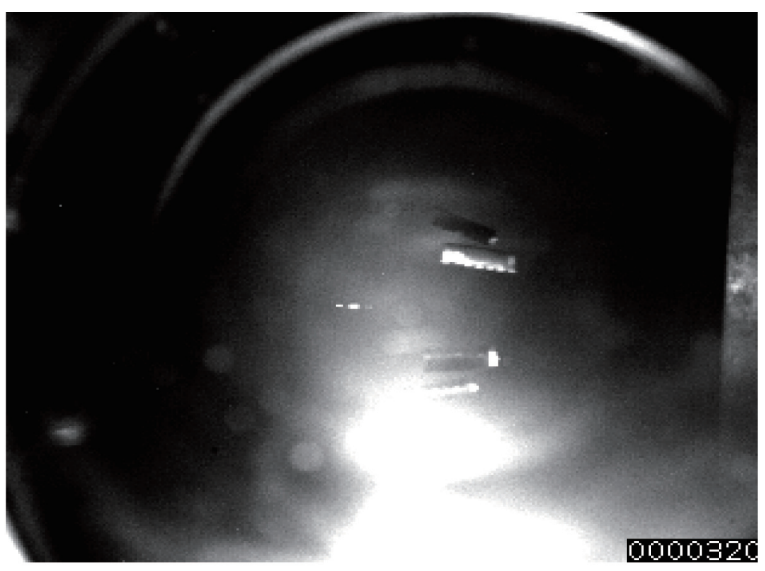

Fig.6. An example of high-speed video image. Projectile was flying from right to left at $1.5 \mathrm{~km} / \mathrm{s}$.

pump tube). As already described, the projectile was launched into open space.

Top picture of Fig. 8 showed Apollo shaped projectile, 2-pieces sabot and retainer ring. The retainer ring holds the sabot so as not to separate before it launch from the muzzle. Bottom picture of Fig.7 showed the example of high-speed video image. The picture clearly indicated the sabot and retainer ring successfully 

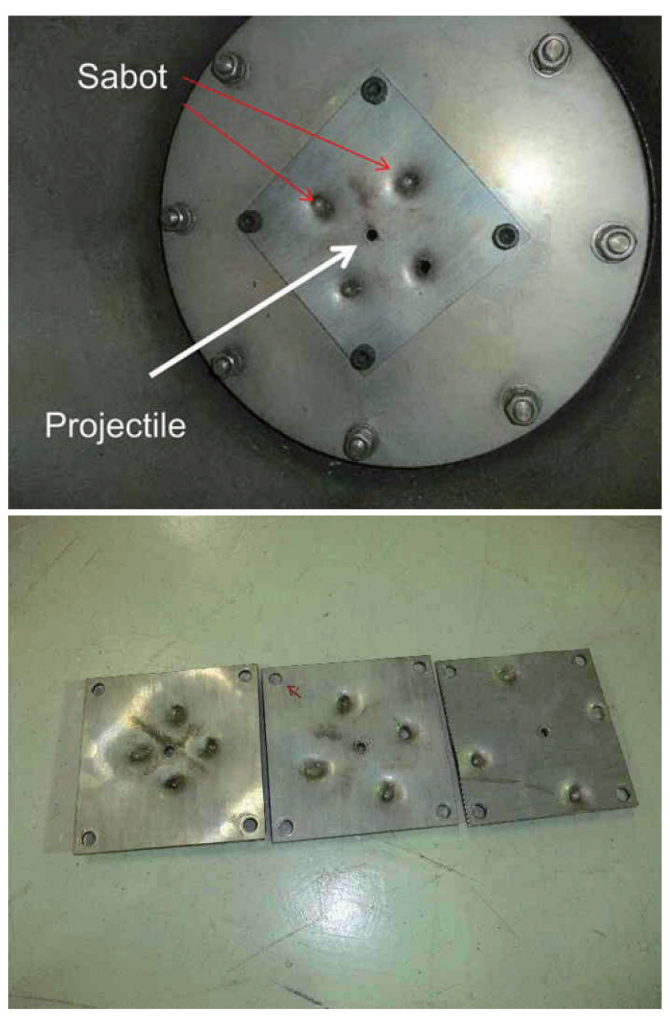

Fig.7. Test plates (mild steel JIS SS400) after shot.
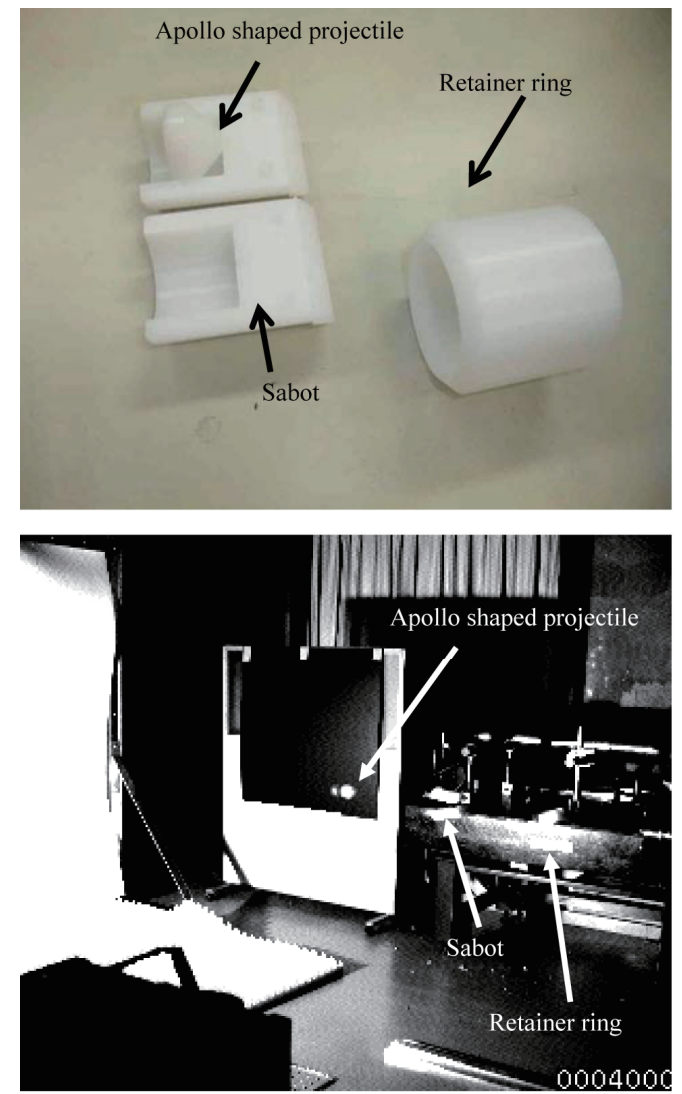

Fig.8. Top: An Apollo shaped projectile, 2-pieces sabot and retainer ring. The retainer ring hold 2-pieces sabot in the launch tube. Bottom: Example of high-speed video image. Sabot and retainer ring was successfully separated from the Apollo shaped projectile. Flight velocity of the projectile was $0.43 \mathrm{~km} / \mathrm{s}$.

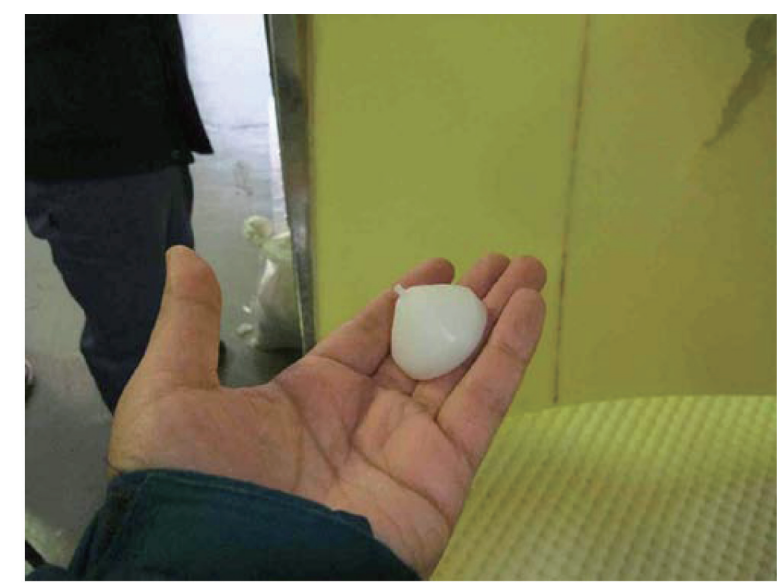

Fig.9. Apollo shaped projectile recovered from the shot.

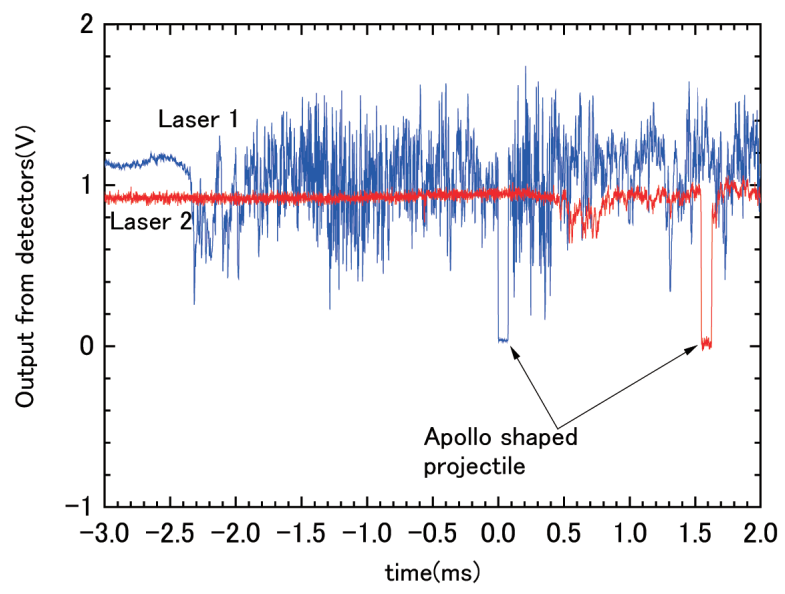

Fig.10. Example of laser detectors outputs. Each laser clearly detected Apollo shaped projectile. Projectile speed $428 \mathrm{~m} / \mathrm{s}$ was obtained from this measurement.

separate from the projectile. With the soft landing system, which was made of Kevler sheets and urethane forms, the projectile was recovered without any damages after the shot (as shown in Fig.9).

Projectile speed was measured through the same instrumentation used for the $15 \mathrm{~mm}$ gun barrel. Fig. 10 showed the example of the laser detector outputs. Measuring time difference between each laser outputs, projectile speed was calculated as shown in the table 3. It should be noted that measured projectile speed was slightly faster than that of predicted by numerical simulation. It means that gas-dynamic or mechanical loss of the $72 \mathrm{~mm}$ gun barrel was negligible. This result was quite different from the results with $15 \mathrm{~mm}$ gun barrel we obtained in the last year, which results showed gas-dynamic and mechanical loss was approximately $40 \%$. We believed that this high-efficiency was caused by the following reasons.

(1) Cross section ration between launch tube (210 $\mathrm{mm}$ diameter) and gun barrel (72mm diameter) was approximately $1 / 9$, which was thought as an optimum ratio for free-piston driver. Low gasdynamic loss was hence obtained with this original designed dimension for HEK.

(2) Low compression ratio for the quite low launch tube pressure (less than $3 \mathrm{MPa}$ ). To obtain quite low lunch tube pressure, 

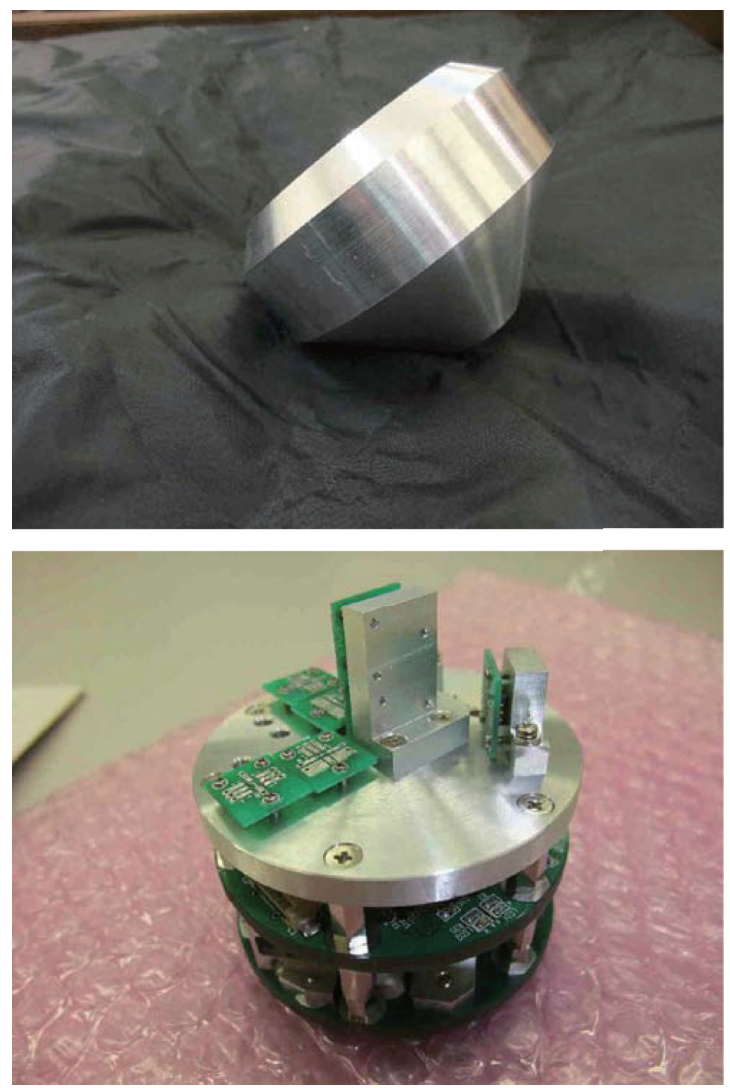

Fig.11. Top: An Apollo shaped projectile for the study on transonic instability of reentry capsules. Bottom: Prototype of the projectile-onboard miniature data logger. Size of the logger is $65 \mathrm{~mm}$ diameter and $60 \mathrm{~mm}$ height.

\begin{tabular}{cc} 
Table 3. Comparison of projectile speed measured and predicted \\
\hline Projectile speed measured \\
Projectile speed predicted & $428 \mathrm{~m} / \mathrm{s}$ \\
& $420 \mathrm{~m} / \mathrm{s}$
\end{tabular}

compression ratio of this operation condition was almost 20, which was the minimum compression ratio for the operation of the free-piston driver. Heat loss in the compression process was thus reduced compared with usual free-piston driver operation, which usual compression ratio is approximately 50 .

\section{Future Plan - Aerodynamic Instability Test -}

For the measurement of aerodynamic instability with reentry capsule models, we are going to use projectiles in which miniature onboard data-logger instrumented. Since the prototype data-logger became bigger than we expected, bore of the gunbarrel is going to increase from $72 \mathrm{~mm}$ to $120 \mathrm{~mm}$. The design of the $120 \mathrm{~mm}$ gun barrel was already finished and performance was evaluated with the quasi-one dimensional numerical code. The projectile going to be use in the study was shown in the upper picture of Fig.10(top figure). The projectile was made of A7075. After the flight test, the model is going to be recovered and reused. Bottom of the Fig.10, prototype of the data-logger was shown. The logger has miniature accelerometers and gyros. It is a standalone measurement system, which can measure 10 -channesl for $500 \mathrm{~ms}$ duration. The logger was design to be shock resistive. Free-flight test with the system was expected in
June or July 2011.

\section{Acknowledgments}

The authors wish to thank to Mr. Mehara, Mr.Narita and Mr. Fujimura who operate the facility.

\section{References}

1) Tanno, H., Komuro, T., Kodera, M., Sato, K. and Itoh, K.: A twostage light gas gun drived from free-piston shock tunnel technology, Proceedings of $49^{\text {th }}$ ISTS.

2) Itoh, K., Ueda, S., Komuro, T., Sato, K., Takahashi, M., Miyajima, H., Tanno, H. and Muramoto, H.: Improvement of a free piston driver for a high-enthalpy shock tunnel, Shock Waves, 8, No.4,1998.

3) Tani, K., Ioth, K., Takahashi, M., Tanno, H., Komuro, T., Miyajima and H.: Numerical study of free-piston shock tunnel performance, Shock Waves, 3, 1994. 